\title{
IMPLEMENTASI PERSEDIAAN BARANG PADA PT.MARKETAMA INDAH MENGGUNAKAN METODE PIECES
}

\author{
${ }^{1}$ Muhamad Padli, ${ }^{2}$ Sugiyono* \\ Teknik Informatika, STIKOM Cipta Karya Informatika \\ Jl.Raden Inten II No.8A, Duren Sawit, Jakarta Timur, Indonesia \\ Mpadli667@gmail.com, inosoguy007@gmail.com,mahvin2012@gmail.com
}

Received: 2021-08-25, Revised: 2021-08-30, Accepted: 2021-09-02

\begin{abstract}
Abstrak
PT. Marketama Indah merupakan perusahaan yang bergerak dibidang industri farmasi dengan memproduksi produk perawatan rumah tangga, perawatan pribadi dan makanan fungsional atau makanan suplemen. Tak sedikit perusahaan yang belum memanfaatkan teknologi perusahaan dengan baik salah satunya pada perusahaan PT. Marketama Indah. Berdasarkan analisa penelitian pada perusahaan PT. Marketama Indah ditemukan permasalahan produk dan pendataan dalam persediaan barang. Karena Proses sistem yang masih manual banyak sekali pemasalahan yang disebabkan oleh hiuman error, seperti dalam menginput pendataan barang memerlukan waktu cukup lama karena masih menggunakan buku lalu diinput ke dalam Microsoft Exel sehingga tidak efisien dan menyebabkan ketidakakuratan. Dari itu penulis mengajukan sistem usulan yang sudah dibangun dan sudah terkomputerisasi atau berbasis WEB. Kemudian diimplementasikan dengan metode PIECES, hasil akhir sistem dapat diakses oleh pegawai dan manager. Juga mberikan informasi yang ada pada gudang secara cepat dan akurat. Kinerja sistempun semakin efektif, efisien hingga bisa meminimalisir terjadinya human error.
\end{abstract}

Kata kunci: Persediaan Barang, Web, PIECES

\begin{abstract}
PT. Marketama Indah is a company engaged in the pharmaceutical industry by producing household care products, personal care and functional foods or food supplements. Not a few companies that have not utilized the company's technology properly, one of which is the company PT. Marketama Indah, Based on research analysis on the company PT. Marketama Indah found product problems and data collection in inventory. Because the system process is still manual, there are many problems caused by human errors, such as inputting data collection it takes a long time because it is still using books and then inputted into Microsoft Excel so that it is inefficient and causes inaccuracies. From that the authors propose a proposed system that has been built and has been computerized or WEBbased. Then implemented with the PIECES method, the final results of the system can be accessed by employees and managers. Also provide information in the warehouse quickly and accurately. The performance of the system is more effective, efficient so that it can minimize the occurrence of human errors.
\end{abstract}

Keywords : Inventory, WEB, PIECES

1. Pendahuluan

This work is licensed under a Creative Commons Attribution 4.0 International License.

http://journal.stmikjayakarta.ac.id/index.php/JMIJayakarta 
DOI: $10.52362 /$ jmijayakarta.v1i4.569

PT. Marketama Indah atau dikenal juga dengan nama Enesis Group merupakan perusahaan berbentuk Perseroan Terbatas. Perusahaan ini didirikan pada tahun 1988 di Jakarta dan berbasis di Kawasan Industri, Pulo Gadung. Perusahaan ini bergerak di industri farmasi dengan memproduksi produk perawatan rumah tangga, perawatan pribadi dan makanan fungsional atau makanan suplemen.

Dalam proses bisnis, teknologi informasi dapat diaplikasikan dengan berbagai cara sesuai kebutuhan perusahaan tersebut. Umumnya perusahaan yang memanfaatkan teknologi informasi dengan baik yaitu perusahaan yang sedang mengembangkan bisnisnya demi kepuasan pelanggan yang dikelolanya selama ini. Penggunaan teknologi informasi dapat digunakan untuk mengatasi masalahmasalah yang terjadi dalam perusahaan tersebut seperti masalah pendataan produk-produk yang dikelolanya untuk diposes kepenjualan.

Namun, tak sedikit perusahaan belum memanfaatkan teknologi informasi dengan baik. Dengan arti lain masih banyaknya masalah-masalah yang muncul akibatnya kurangnya pengaplikasian teknologi informasi. Banyak perusahaan yang sedang mengembangkan eksistensinya dibidang bisnis yang masih kesulitan mempergunakan teknologi informasi salah satunya perusahaan dibidang bisnis yaitu PT.Marketama Indah. Pada perusahaan ini masih banyak bermunculan masalah seperti plus minusnya produk dalam pendataan penyediaan produknya. Proses yang manual banyak sekali permasalahan yang disebabkan oleh human error. Sehingga perlu dibuatnya inovasi dengan teknologi berbasis WEB yang dapat mempermudah sistem kerja pendaatan persediaan barang pada PT.Marketama Indah yang hanya dapat diakses oleh pegawai dan manager. Sistem ini dapat diakses sesuai kebutuhan internal. Lalu diimplementasikan untuk mempermudah pegawai dan manager gudang dalam mengelola data dan laporan barang, selain itu data barang hanya dapat diubah atas izin manager serta administrator pada sistem dapat menghapus semua data yang ada pada database. Sistem persediaan barang ini peneliti menggunakan sistem usulan dengan metode PIECES dalam mengatasi peramasalahan yang ada pada PT. Marketama Indah guna meningkatkan kinerja sistem yang lebih maksimal dalam pendataan dan laporan persediaan barang .

\section{Tinjauan Literatur}

Penelitian terdahulu dilakukan oleh Inge Handriani, Sitiani Zalukhu, yang berjudul "Analisa Dan Perancangan Aplikasi Sistem Inventory (Studi Kasus: Pt. Cakra Medika Utama) [1] Berdasarkan penelitian tersebut yaitu Pada perancangan sistem informasi inventory ini dapat membantu meningkatkan efisiensi waktu dalam memberikan informasi ketersediaan stok barang yang ada di gudang secara cepat dan akurat.

Penelitian terdahulu dilakukan oleh Fitri Herawati, Yaya Sudarya Triana yang berjudul "Analisa Dan Perancangan Bolt Inventory Manajement System: Pt. Internux." [2] Berdasarkan penelitian tersebut yaitu dapat mengelola seluruh aktifitas keluar masuk barang, stok barang dan laporan. Dan dapat menangani seluruh permasalah yang telah di uraikan.

Penelitian terdahulu dilakukan oleh Ari WibowoYuwan Jumaryadi yang berjudul "Analisa Dan Perancangan Sistem Informasi Inventory Penjualan Dan Pembelian Perangkat Komputer Berbasis Web (Studi Kasus: Pt. Stefan Mandiri Perkasa)" [3] Berdasarkan penelitian tersebut yaitu Dengan adanya rancangan sistem ini, dapat membantu berlangsungnya proses bisnis perusahaan.

Penelitian terdahulu dilakukan oleh Siti Ernawati, Rizky Gumelar yang berjudul "Analisa Pieces Untuk Rancang Bangun Sistem Informasi Monitoiring Persediaan Barang Berbasis Web Pada Koperasi Sartika Bogor" [4] Berdasarkan penelitian tersebut yaitu membantu koperasi dalam hal monitoring persediaan barang dan pelaporan data stok menjadi lebih cepat dan akurat. Untuk mengetahui manfaat yang dirasakan dalam membangun sistem usulan peneliti menggunakan analisa pieces agar sistem yang diusulkan dapat memberikan manfaat yang maksimal dalam mengatasi masalah yang ada pada koperasi.

Penelitian terdahulu dilakukan oleh Lila Setiyani, Yeny Rostiani,Tri Ratnasar yang berjudul "Analisis Kebutuhan Fungsional Sistem Informasi Persediaan Barang Perusahaan General Trading (Studi Kasus : PT. Amco Multitech) [5] Berdasarkan penelitian tersebut yaitu Penelitian ini 
DOI: $10.52362 / j m i j a y a k a r t a . v 1 i 4.569$

menghasilkan daftar kebutuhan fungsional sistem persediaan barang, yang dapat di implementasikan pada PT. Amco Multitech untuk pengelolaan persediaan barang.

Penelitian terdahulu dilakukan oleh Anwardi, Anggi Ramadona, Misra Hartati, Tengku Nurainun, Ekie Gilang Permata yang berjudul "Analisis PIECES dan pengaruh website Fikri Karya Gemilang Terhadap Sistem Promosi Menggunakan Model Waterfall" [6] Berdasarkan penelitian tersebut yaitu bahwa terdapat tingkat kepuasan konsumen terhadap penerapan sistem promosi manual kurang optimal, dan penerapan sistem promosi usulan memberikan peningkatan terhadap kepuasan konsumen. Berdasarkan uji paired sample t-test maka dapat disimpulkan bahwa nilai Sig (2-tailed) sebesar 0.0000015 yang berarti terjadi perbedaan yang signifikan antara penerapan sistem promosi tradisional dengan sistem promosi usulan berbasis internet.

Penelitian terdahulu dilakukan Ahmad Arif Nurrahman, Otong Rukmana. Indra Ahmad Fauzi oleh yang berjudul" Perancangan Sistem Informasi Gudang Barang Jadi Di Pt Remaja Rosdakarya" [7] Berdasarkan penelitian tersebut yaitu Dengan dirancangnya sistem ini, diharapkan dapat membantu perusahaan dalam mengelola data gudang.

Penelitian terdahulu dilakukan oleh Asep Muhammad Indra Purnama, S.T., M.Kom, Deni Hidayat yang berjudul "Perancangan Sistem Informasi Inventori Gudang Kain Pt. Nasional Sandang Textile " [8] Berdasarkan penelitian tersebut yaitu Penelitian ini menghasilkan sebuah sistem informasi inventori yang dapat memudahkan pencatatan transaksi pembelian, penjualan dan data barang. Hasil akhir dari penelitian ini adalah terbuatlah sistem informasi inventori gudang kain PT. Nasional Sandang Textile

Penelitian terdahulu dilakukan oleh Iyus Maida Manalu, Akmaludin yang berjudul "Perancangan Sistem Informasi Inventory Pada Gudang Consumable Pada Pt. Umbul Rejeki Cikarang" [9] Berdasarkan penelitian tersebut yaitu dengan adanya sistem informasi inventory pada gudang consumable ini diharapkan, agar didalam pengelolaan inventory menjadi lebih mempermudah karyawan dan meningkat kinerja karyawan.

Penelitian terdahulu dilakukan oleh Effan Najwaini, Purnama, Nur Rizki Aulia yang berjudul "Perancangan Sistem Informasi Persediaan Barang Berbasis Web pada Alzena Hijab Store Banjarmasin" [10] Berdasarkan penelitian tersebut yaitu menghasilkan sebuah sistem informasi persediaan barang berbasis website yang memberikan kemudahan dalam mengelola persediaan barang

Penelitian terdahulu dilakukan oleh fahrisal, Sentosa Pohan, S.Kom.,M.Kom, Marnis Nasution, S.Kom.,M.Kom yang berjudul "Perancangan Sistem Inventory Barang PadaUd. Minang Dewi Berbasis Website" [11] Berdasarkan penelitian tersebut yaitu Perancangan sistem dilakukan dengan metode waterfall yang merupakan model pengembangan sistem informasi yang sistematik dan sekuensial.

Penelitian terdahulu dilakukan oleh Syahri Ramadhani, Wahyu A. Kusuma yang berjudul "PIECES Framework untuk Analisa Tingkat Kepuasan Pengguna dan Kepentingan Sistem Informasi [12] Berdasarkan penelitian tersebut yaitu ni adalah Pengaplikasian PIECES Framework dengan mengukur tingkat kepentingan dan kepuasan pada SIM PKN Teknik informatika UMM. Hasil Penelitian ini menunjukan bahwa Tanggapan pengguna tentang SIM PKN sangat baik dengan rata rata pada tingkat kepuasan sebesar 4.03 dan tingkat kepentingan sebesar 4.19.

Penelitian terdahulu dilakukan oleh Lukman Nulhakim, Nur Azizah, Mety Trisna Ajijah yang berjudul "Sistem Informasi Monitoring Inventory Dengan Analisa Pieces Pada PT. Care Spundbond “ [13] Berdasarkan penelitian tersebut yaitu monitoring inventory barang dengan menggunakan metode analisa Pieces yaitu dengan menganalisa layak atau tidak dari penerapan monitoring pada proses pengolaan penyewaan gudang.

Penelitian terdahulu dilakukan oleh Yuntari Purba Sari yang berjudul "Rancang Bangun Aplikasi Penjualan Dan Persediaan Obat Pada APOTEK MERBEN" [14] Dengan adanya Aplikasi Penjualan dan Persediaan Obat diharapkan dapat membantu staff ataupun user dalam pengolahan data penjualan, laporan obat keluar, laporan obat masuk, dan laporan cek stok obat.

Penelitian terdahulu dilakukan oleh Abdul Hafidh Sidiq, Ana Kurniawati ” Analisis Kebutuhan Sistem Administrasi Bagian Sidang Ujian Universitas GUNADARMA Dengan Metode PIECES" [15] 
DOI: $10.52362 /$ jmijayakarta.v1i4.569

Setelah melakukan analisis dengan metode PIECES, dapat disimpulkan bahwa Sistem administrasi yang sekarang digunakan oleh Bagian Sidang Ujian, Universitas Gunadarma perlu dibenahi dan diperbaiki agar proses administrasinya dapat terselenggara dengan efisien dan efektif. Pembenahan dan perbaikan yang sebaiknya dilakukan adalah dengan mengembangkan sistem administrasi berbasis web.Dalam menganalisa sistem tersebut ada enam indikoator yang digunakan untuk mengatsi permaslahan yang ada diantaranya Performance (kinerja), Information (Informasi), Economic (ekonomi), Control (pengendalian), Efficiency (efisien), Service (layanan).

Berikut ini adalah penejlesan enam indicator tersebut yaiutu:

1. Performance (Kinerja): menilai apakah strategi saat ini masih memungkinkan untuk me ningkatkan kinerjanya. Untuk kinerja ini, diperkirakan dengan throughput, yaitu jumlah pekerjaan/hasil/harapan yang dapat dilakukan/diciptakan pada waktu tertentu, yaitu waktu yang diperlukan untuk menyelesaikan serangkaian latihan untuk memberikan hasil hasil output/deliverables terntentu

2. Information (informasi): menilai apakah metodologi saat ini dalam dapat dikerjakan sehingga kualitas informasi yang didapatkan menjadi lebih baik. Yang ang dimaksud kualitas informasi yang semankin meningkat adalah yang lebih efisien, tepat, relevan, dan lengkap juga diperkenalkan dengan cara yang tepat waktu.

3. Ekonomic (ekonomi) : mengevaluasi apakah sistem saat ini dalam hal apa pun dapat diperluas dalam manfaatnya (nilai kegunaanya) atau menurunkan biaya pelaksanaannya.

4. Control (pengendalian) : mensurvei apakah sistem saat ini masih bisa ditingkatkan sehingga kualitas penegndaliannya semakin meningkat, dan kapasitasnya untuk mengidentifikasi kesalahan/kecurangan juga menjadi lebih baik.

5. Efficiency (efisiensi): menilai apakah prosedur yang ada saat ini masih dapat diperbaiki, sehingga tercapai peningkatan efisiensi operasi.

6. Service (layanan): menilai apakah prosedur yang ada saat ini masih dapat diperbaiki kemampuannya untuk mencapai peningkatan kualitas layanan.

\section{Metode Penelitian}

Penelitian ini ini menggunakan metode PIECES untuk menentukan sistem persedian barang yang akan dibuat. Langkah-langkah untuk menyelesaikan penelitian dan pengujian yang dilakukan adalah:

1. Mengumpulkan Data

Penulis melakukan pengamatan langsung ke lokasi penelitian untuk mendapatkan segala sesuatu baik data, masalah maupun struktur organisasi yang akan digunakan untuk melakukan penelitian. Data yeng terkait yaitu pendataan dan laporan barang, serta proses data barang masuk dan barang keluar.

2. Analisa Sistem

Proses analisa yang dilakukan, ada dua tahapan, khususnya penelitian terhadap analisa sistem berjalan dan analisa terhadap sistem yang diusulkan. Dalam analisis sistem berjalam peneliti menggunakan tahapan sistem metode PIECES yang mana akan menghasilkan bentuk kemudian dibuat sistem usulan yang dibangun.

c. Pemodelan Sistem

Tahapan ini merupakan langkah dari pembuatan model pada sistem persediaan barang

d. Merancang Sistem

Proses merancang sistem ini, dilakukan untuk membuat aplikasi sistem persediaan barang yang bisa diakses sesuai dengan kebutuhan internal pada perusahaan PT. Marketama Indah.

e. Pengujian Sistem

Tahapan ini, merupakan Proses pengujian sistem dilakukan agar menghindari human error atau kesalahan, dan sistem yang dibuat sesuai dengan kebutuhan perusahaan PT.Marketama Indah

\section{Hasil dan Pembahasan}




\subsection{Tempat Penelitian}

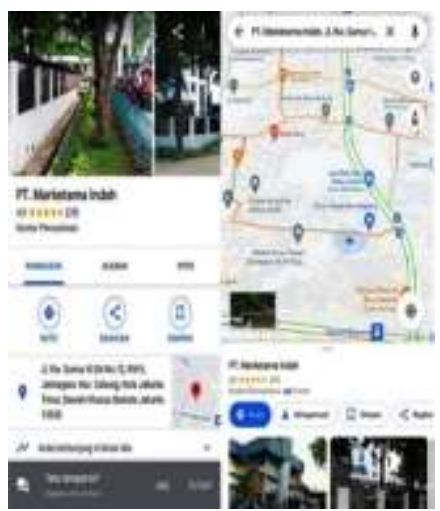

Gambar 4.1 Lokasi Penelitian

Gambar diatas merupakan lokasi tempat penilitian dilakukan pada PT.Marketama Indah atau dikenal juga dengan nama Enesis Group merupakan perusahaan berbentuk Perseroan Terbatas. Perusahaan ini didirikan pada tahun 1988 di Jakarta dan berbasis di Kawasan Industri, Pulo Gadung.Perusahaan ini bergerak di industri farmasi dengan memproduksi produk perawatan rumah tangga, perawatan pribadi dan makanan fungsional atau makanan suplemen. Yamg terletak di Jl. Rw. Sumur III Dd No.12, RW.9, Jatinegara, Kec. Cakung, Kota Jakarta Timur, Daerah Khusus Ibukota Jakarta 13930

\subsection{Analisa Sistem Berjalan}

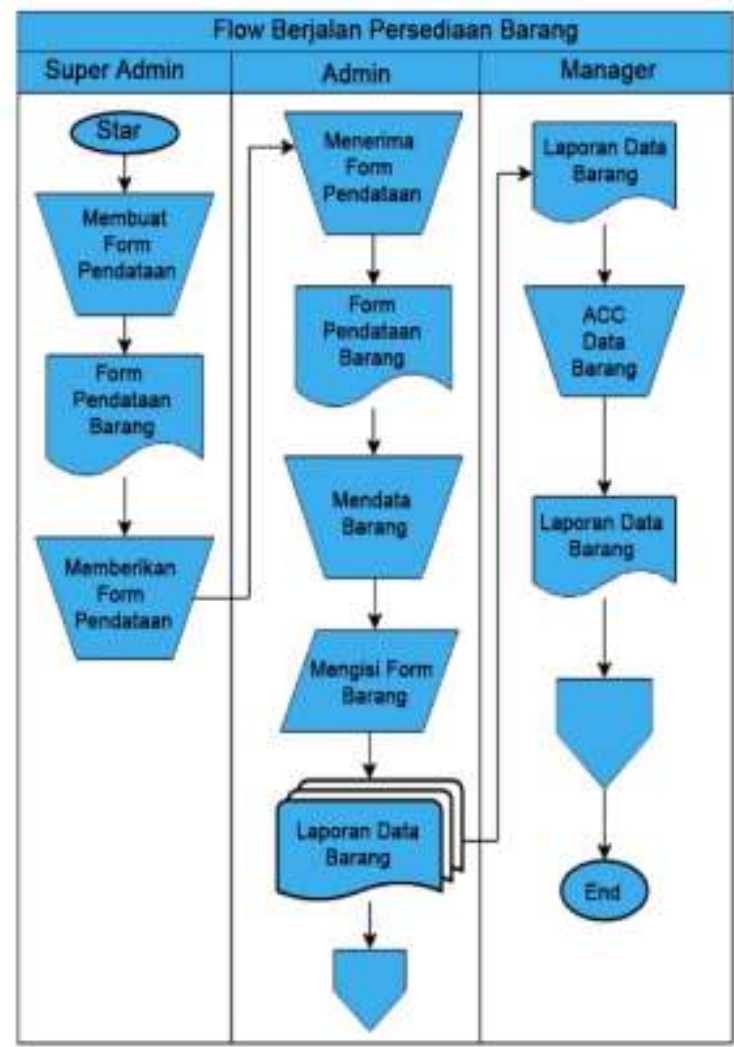

Gambar 4.2 Flow Sistem Berjalan

Gambar diatas merupakan flowmap berjalan persediaan barang pada PT. Marketama Indah berdasarkan hasil pengamatan penulis, ada beberapa user yang berperan dalam sistem

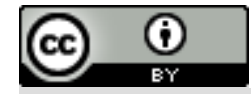

This work is licensed under a Creative Commons Attribution 4.0 International License.

http://journal.stmikjayakarta.ac.id/index.php/JMIJayakarta 
tersebut berikut ini merupakan alur sistem kerjanya yaitu Form pendataan barang yang dibuat oleh super admin, kemudian diserahkan ke admin untuk selanjutnya diisi oleh admin setelah melakukan pendataan barang, kemudian laporan data barang disampaikan ke manager, sampai manager menyetujui atau acc laporan data barang.

\subsection{Sistem yang di Usulkan}

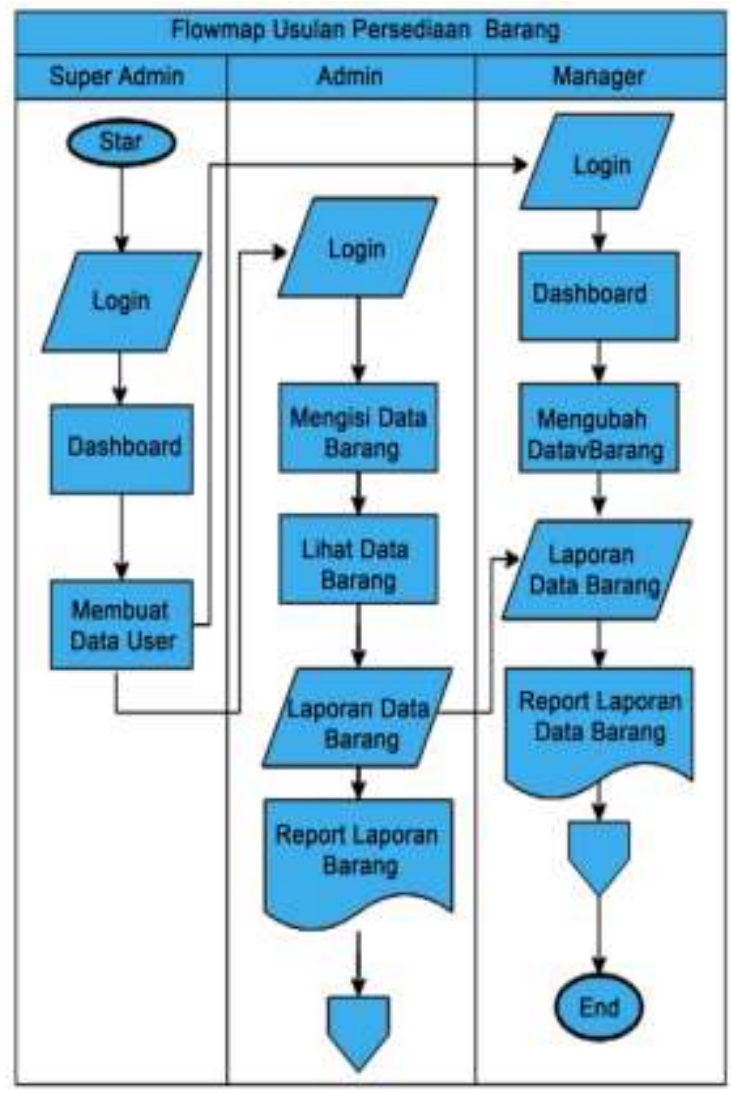

Gambar 4.3 Sistem Usulan

Gambar diatas merupakan Sistem usulan berdasrkan hasil analisa persedian barang jadi yang ada digudang PT. Marketama Indah dalam flow usulan terdapat bebrapa peran actor berdasarkan bagiannya diantaranya :

1. Super Admin yaitu Level user khusus yang dapat bertugas mengatur level-level user lainnya untuk mengoperasikan aplikasi tersebut.

2. Admin Gudang yaitu Admin Gudang yang terdaftar dalam aplikasi yang diberi hak akses sesuai dengan bagian pekerjaan petugas tersebut. Untuk mengoperasikan rekapan data barang keluar masuk. 3. Manager Gudang yaitu Dapat mengatur data detail barang. Mulai dari harga, stok, dan juga mengelola datanya 


\subsection{Use Case Diagram}

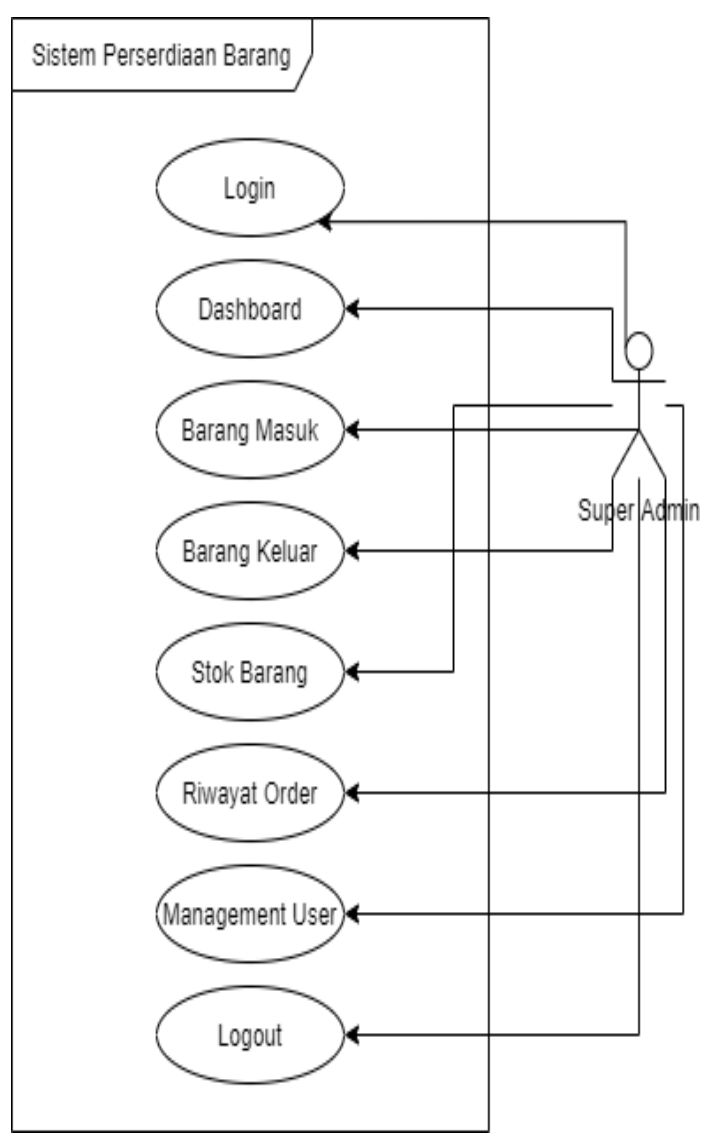

This work is licensed under a Creative Commons Attribution 4.0 International License. http://journal.stmikjayakarta.ac.id/index.php/JMIJayakarta 
DOI: 10.52362/jmijayakarta.v1i4.569

Gambar 4.4 Use Case Super Admin

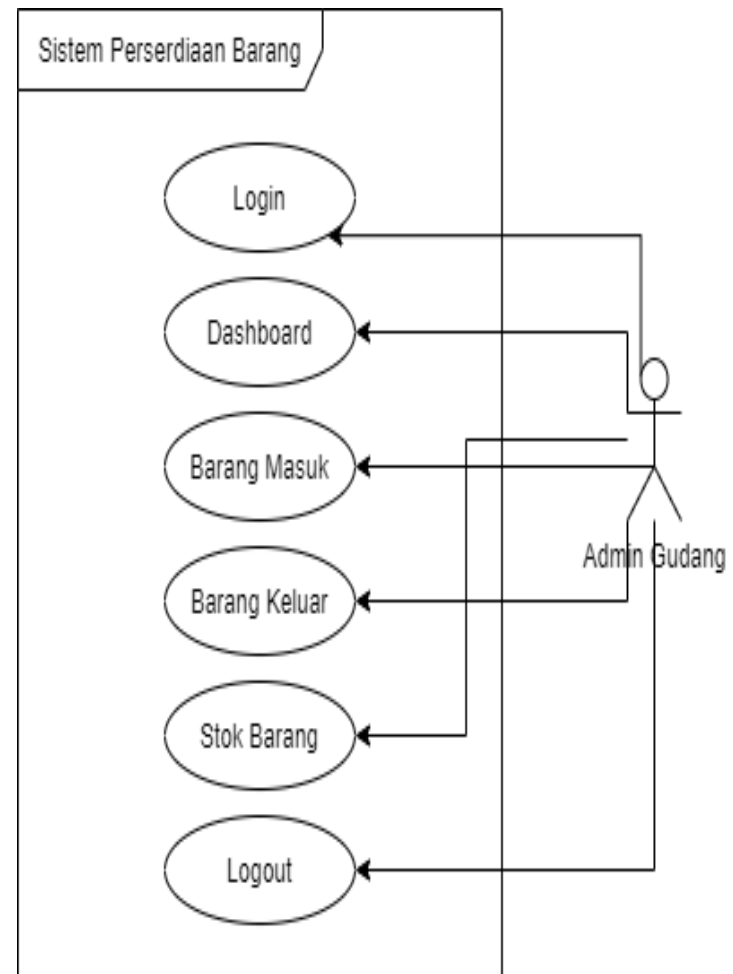

Gambar 4.5 Use Case Admin Gudang

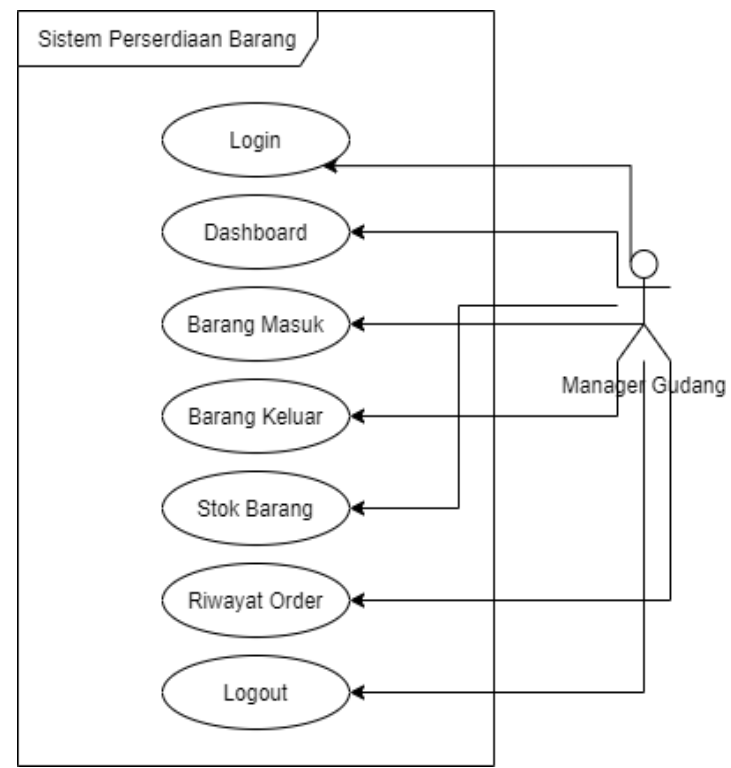

Gambar 4.6 Use Case Manager Gudang

\subsection{Activity Diagram}

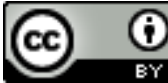

This work is licensed under a Creative Commons Attribution 4.0 International License. http://journal.stmikjayakarta.ac.id/index.php/JMIJayakarta 
DOI: $10.52362 /$ jmijayakarta.v1i4.569

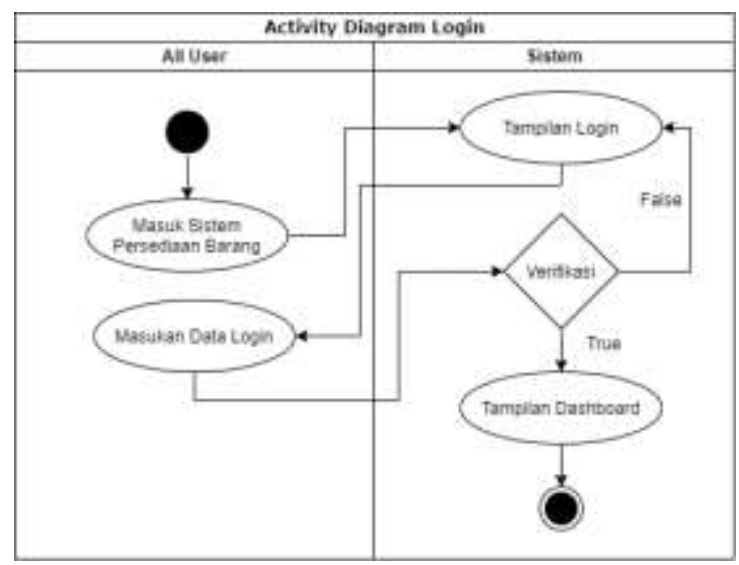

Gambar 4.7 Activity Diagram Login

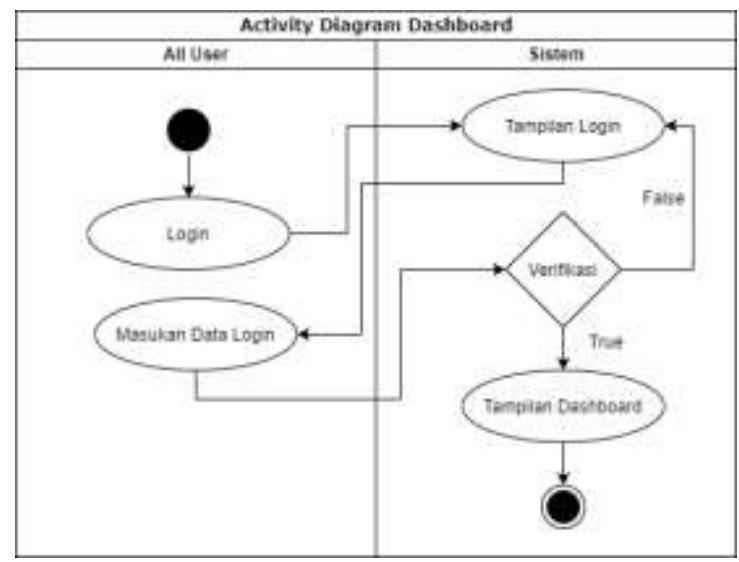

Gambar 4.8 Activity Diagram Dashboard

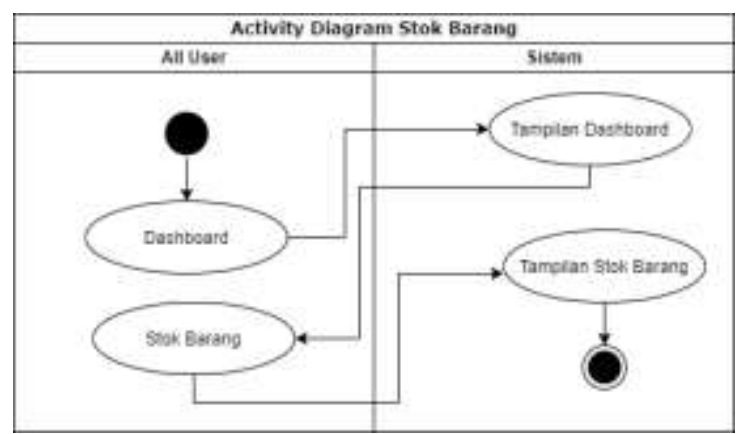

Gambar 4.9 Activity Diagram Stok Barang 
DOI: $10.52362 / j m i j a y a k a r t a . v 1 i 4.569$

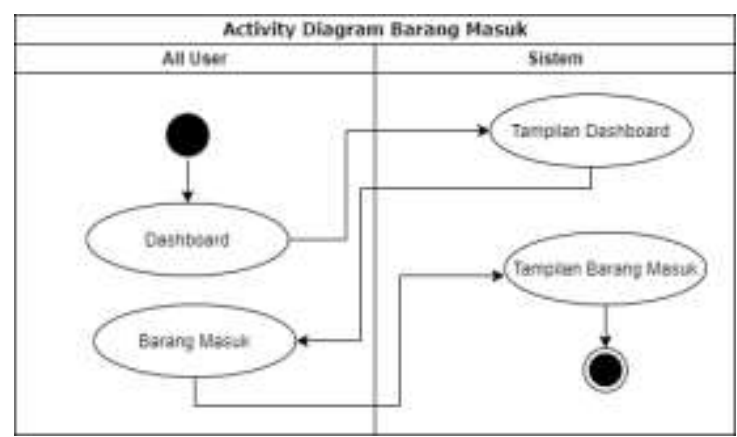

Gambar 4.10 Activity Diagram Barang Masuk

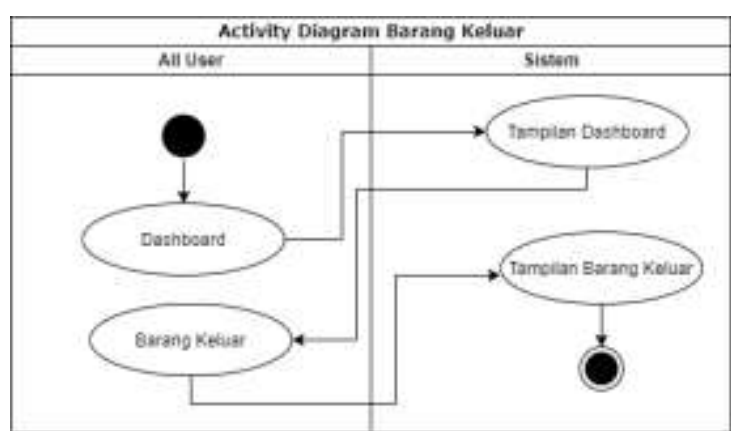

Gambar 4.11 Activity Diagram Barang Keluar

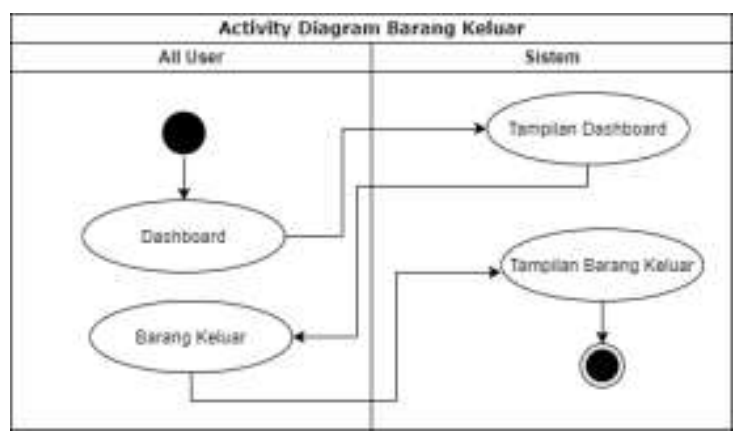

Gambar 4.12 Activity Diagram Tampilan Riwayat Order

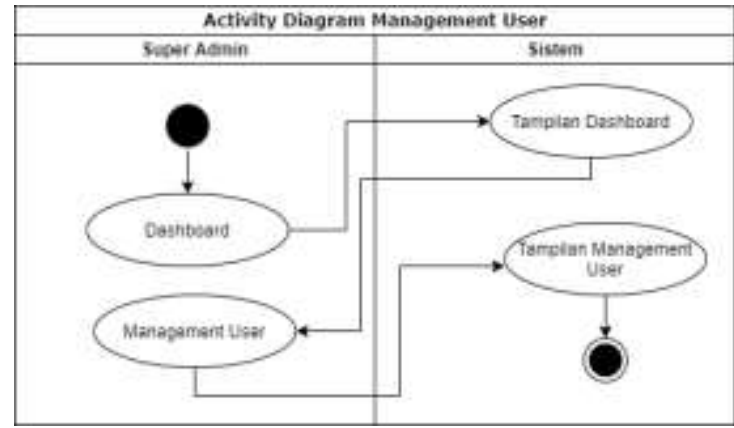

Gambar 4.13 Activity Diagram Tampilan Mamanagement User 
DOI: 10.52362/jmijayakarta.v1i4.569

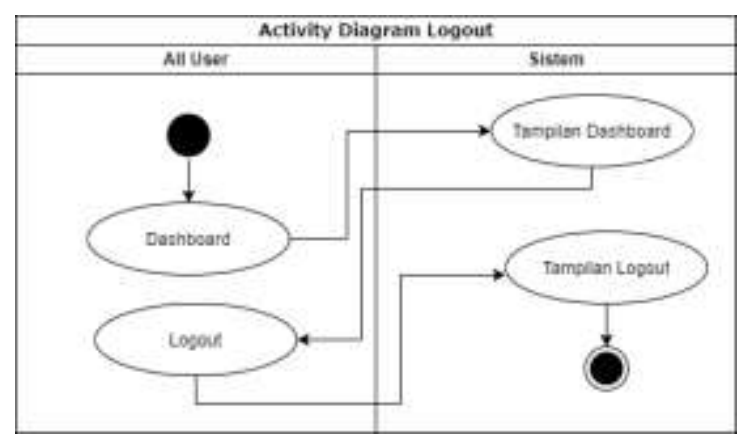

Gambar 4.14 Activity Diagram Tampilan Logout

\subsection{Squance Diagram}

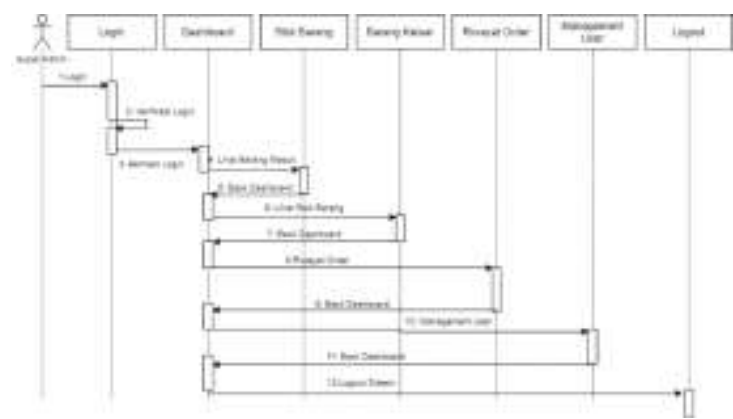

Gambar 4.15 Squance Diagram super Admin

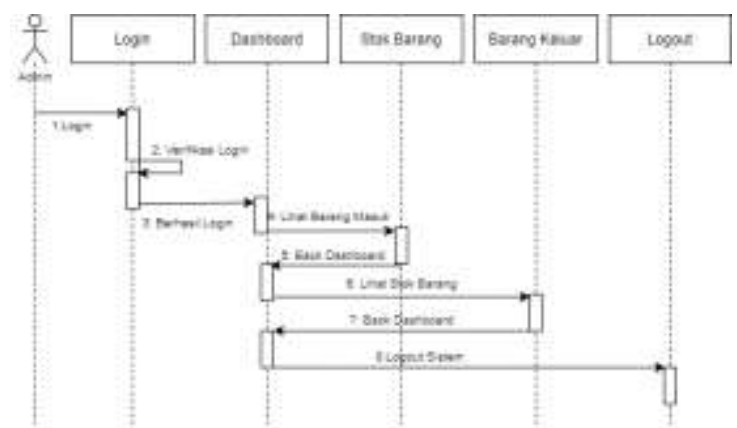

Gambar 4.16 Squance Diagram Admin

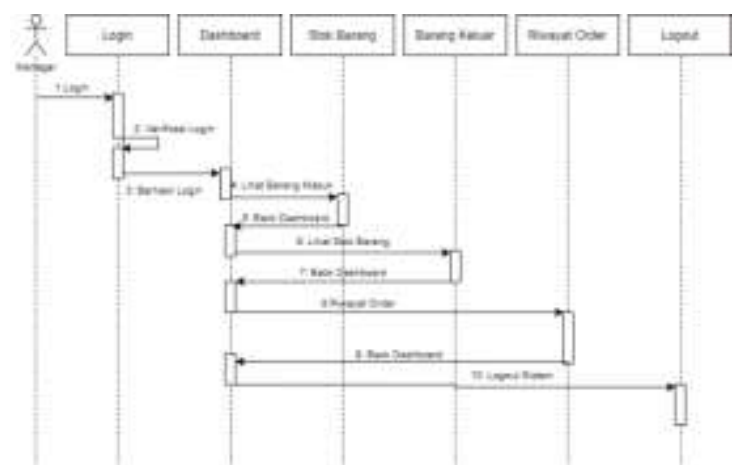

Gmabar 4.17 Squance Diagram Manager

\section{(c)


DOI: $10.52362 / j m i j a y a k a r t a . v 1 i 4.569$

\subsection{Hasil Penerpan Analisa Metode PIECES}

4.7.1 Performance (Kinerja) yaitu menilai sejau mana kinerja yang ditingkatkan untuk menghasilkan tujuan yang diinginkan oleh perusahaan

Tabel 4.7.1 Hasil Analisa Performance

\begin{tabular}{|c|c|}
\hline Sistem Berjalan & Sistem Ususlan \\
\hline $\begin{array}{l}\text { Proses pencatatan } \\
\text { stok menggunakan } \\
\text { kertas ata buku lalu } \\
\text { diinput ke dalam } \\
\text { MS.Exel }\end{array}$ & $\begin{array}{l}\text { Menggunakan sistem } \\
\text { yang sudah } \\
\text { terkomputerisasi }\end{array}$ \\
\hline
\end{tabular}

4.7.2.Information (Informasi) yaitu dari sistem yang dibangun dapat menghasilkan output seperti informasi yang bermanfaat agar perusahaan dapat menyikapi peluang yang ada dan menangani maslah yang terjadi.

Tabel 4.7.2 Hasil Analisa Informasi

\begin{tabular}{|c|c|}
\hline Sistem Berjalan & Sistem Usulan \\
\hline $\begin{array}{l}\text { Proses laporan stok } \\
\text { ke pimpinan belum } \\
\text { terkomputerisasi dan } \\
\text { memerlukan } \\
\text { pencarian data stok } \\
\text { barang }\end{array}$ & $\begin{array}{l}\text { Pada sistem usulan } \\
\text { terdapat menu cetak } \\
\text { dimana actor dapat } \\
\text { memilih barang atau } \\
\text { data barang yang akan } \\
\text { di print untuk } \\
\text { dilaporkan }\end{array}$ \\
\hline
\end{tabular}

4.7.3. Hasil Analisa Ekonomy (Economi) Dalam proses analisa ini selalu mengenai persoalan ekonomi yang berkaitan dengan masalah biaya

Tabel 4.5.3 Hasil Analisa Economy (Ekonomi)

\begin{tabular}{|c|c|}
\hline Sistem Berjalan & Sistem Usulan \\
\hline \begin{tabular}{lr}
\multicolumn{3}{c}{ Dalam penyimpanan } \\
data masih manual \\
seperti & Hard \\
duplicate & atau \\
duplikat, & \\
membutuhkan biaya \\
Seperti r kertas. \\
dicetak rak \\
Mengganti Memori \\
PC Ketika sudah \\
penuh dan tidak \\
dapat menahan \\
substansi informasi
\end{tabular} & $\begin{array}{l}\text { Dalam penyimpanan data } \\
\text { sistem informasi usulkan, } \\
\text { pemnyimpanan data } \\
\text { menggunakan database, } \\
\text { sehingga } \\
\text { informasi data-data } \\
\text { terorganisir dan lebih } \\
\text { produktif selama rentang } \\
\text { waktu yang signifikan } \\
\text { dan tidak perlu banyak } \\
\text { pegawai ran } \\
\text { memasukkan informasi } \\
\text { atau data-data yang } \\
\text { diperlukan. }\end{array}$ \\
\hline
\end{tabular}


DOI: $10.52362 / j m i j a y a k a r t a . v 1 i 4.569$

4.7.4 Control (Keamanan) yaitu proses ini dilakukan untuk meningkatkan kinerja, mencegah kesalahan yang terjadi dan menjamin keamanan atau kerahasiaan data perusahaan

Tabel 4.7.4 Control (Keamnan)

\begin{tabular}{|c|c|}
\hline Sistem Berjalan & Sistem Usulan \\
\hline \begin{tabular}{lr}
\multicolumn{2}{l}{ Keamanan } \\
informasi & belum \\
dipastikan & aman, \\
dengan & alasan \\
tidak & ada \\
penguatan & backup \\
data dan & semua \\
catatan & yang \\
belum ada di \\
kertas ran \\
struktur $r$ atinan \\
cetak sehingga \\
ada kelemahan \\
atau kerusakan \\
data-data \\
dokumen
\end{tabular} & $\begin{array}{l}\text { Keamanan yang } \\
\text { diberikan dalam sistem } \\
\text { usulkan ini lebih terjamin } \\
\text { karena adanya bantuan } \\
\text { back up data dan untuk hak } \\
\text { akses dalam memanfaatkan } \\
\text { sistem informasi semakin } \\
\text { jelas karena kehadiran } \\
\text { nama pengguna dan kata } \\
\text { sandi untuk setiap user. }\end{array}$ \\
\hline
\end{tabular}

4.7.5. Effeciency (Efisien) yaitu menilai prosedur yang ada masih bisa diperbaiki, dan sistem lebih unggul

Tabel 4.7.5 Hasil Analisa Efficiency (Efisien)

\begin{tabular}{|c|c|}
\hline $\begin{array}{l}\text { Sistem } \\
\text { Berjalan }\end{array}$ & Sistem Usulan \\
\hline $\begin{array}{l}\text { Proses pencarian } \\
\text { data atau laporan } \\
\text { persediaan barang } \\
\text { yang manual } \\
\text { memerlukan } \\
\text { waktu yang lama }\end{array}$ & $\begin{array}{l}\text { Proses pencarian data } \\
\text { persediaan barang } \\
\text { mempermudah sistem } \\
\text { kerja dan meningkatkan } \\
\text { efisiensi waktu, karena } \\
\text { dalam sistem usulan } \\
\text { terdafat fungsi pencarian } \\
\text { data, informasi barang } \\
\text { yang sudah menipis atauy } \\
\text { kosong dalam mengontrol } \\
\text { stok barang }\end{array}$ \\
\hline
\end{tabular}

4.7.6. Service (Pelayanan) yaitu mudah dipakai atau use friendly, mudah dipelajari hingga meningkatkan pelayanan bagi pengguna sistem.

Tabel 4.7.6 Service (Pelayanan)

\begin{tabular}{|l|l|}
\hline Sistem Berjalan & Sistem Usulan \\
\hline
\end{tabular}


DOI: 10.52362/jmijayakarta.v1i4.569

\begin{tabular}{|l|lr|}
\hline Keterlambatan & \multicolumn{2}{|l|}{ Sistem informasi yang } \\
dalam & diusulkan mengurangi \\
melaporkan data & keteralambatan dalam \\
persediaan & melaporkan rata \\
kepada atasan. & $\begin{array}{l}\text { persediaan } \\
\text { atasan sehingga dapat }\end{array}$ \\
& meningkatkan pelayanan \\
\end{tabular}

\subsection{Tampilan Pengujian Program}

Di bawah ini merupkan hasil tampilan layout program dari hasil rancangan yang dibuat berdasarkan Analisa metode PIECES diantarnya yaitu :

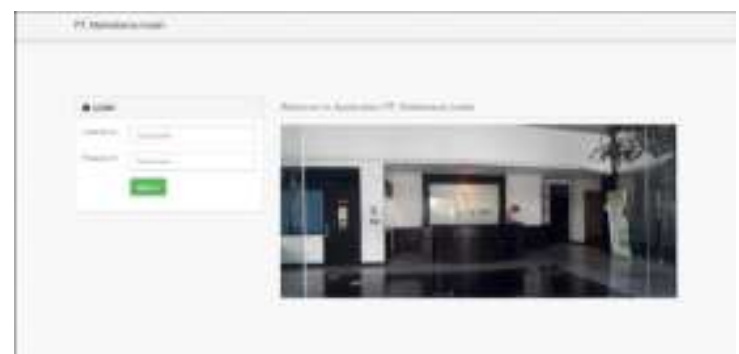

Gambar 4.18 Tampilan Login

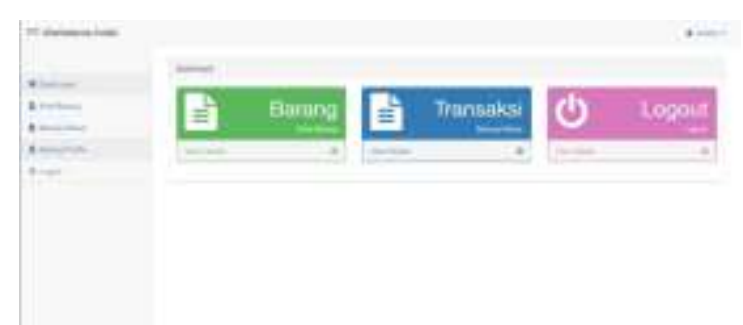

Gambar 4.19 Tampilan Dashboard Admin
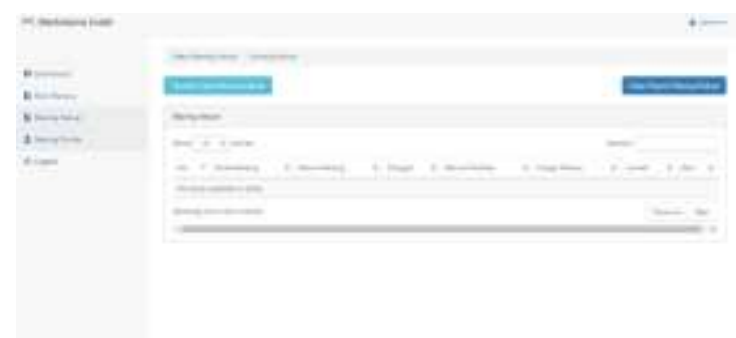

Gambar 4.20 Tampilan Stock Barang Admin 
DOI: $10.52362 / j m i j a y a k a r t a . v 1 i 4.569$
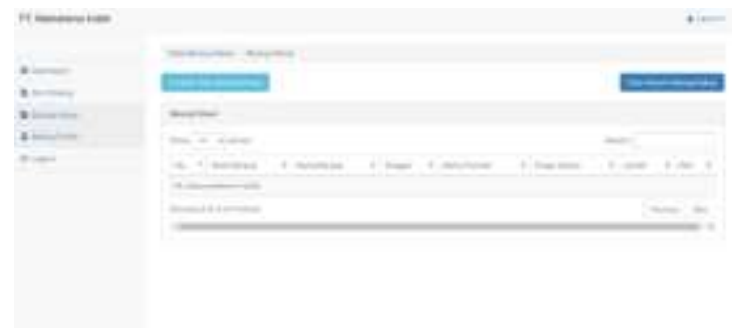

Gambar 4.21 Tampilan Barang Keluar Admin

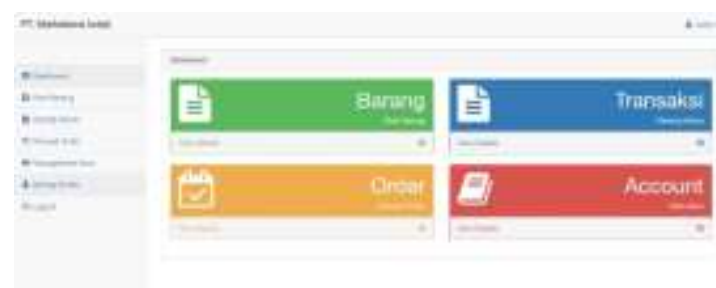

Gambar 4.22 Tampilan Dashboard Super Admin

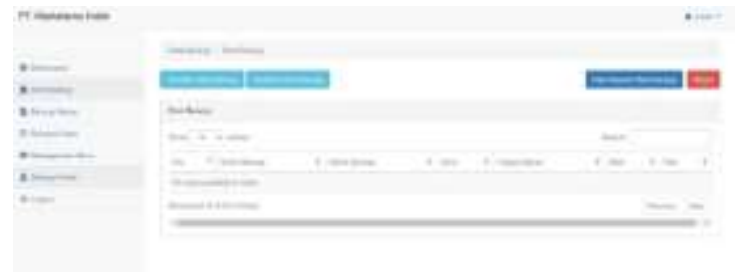

Gambar 4.23 Tampilan Stok Barang Admin

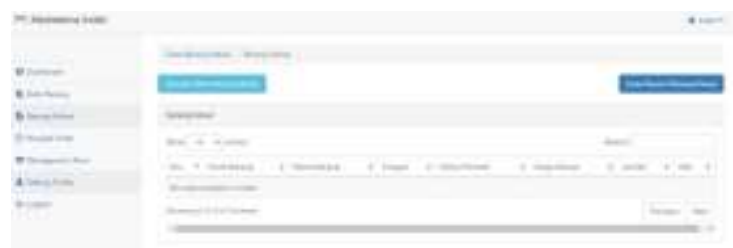

Gambar 4.24 Tampilan Barang Keluar super Admin

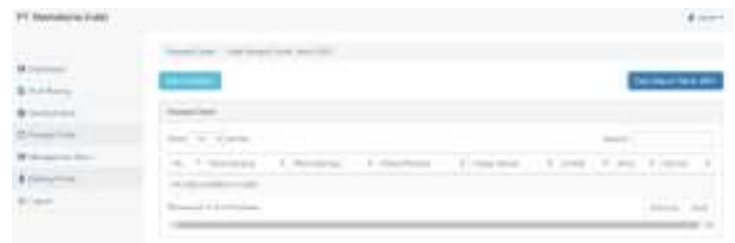

Gambar 4.25 Tampilan Riwayat Order Super Admin

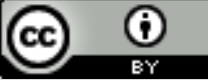

This work is licensed under a Creative Commons Attribution 4.0 International License. http://journal.stmikjayakarta.ac.id/index.php/JMIJayakarta 
DOI: $10.52362 / j m i j a y a k a r t a . v 1 i 4.569$

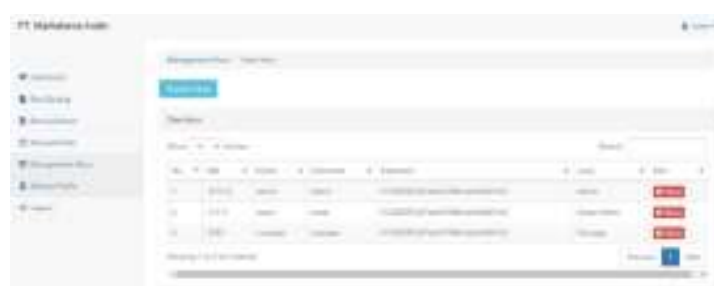

Gambar 4.26 Tampilan Management User

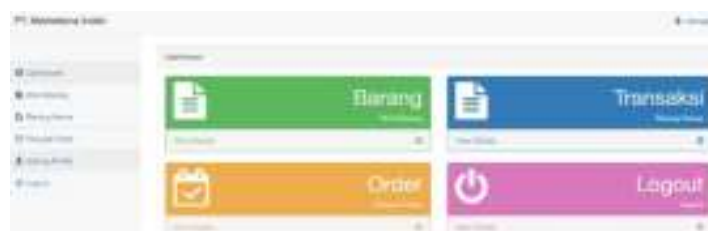

Gambar 4.27 Tampilan Dashboard Manager

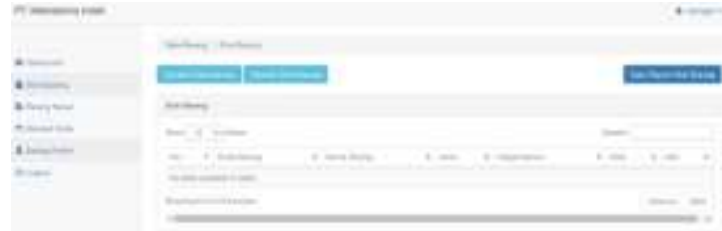

Gambar 4.28 Tampilan Stok barang Manager

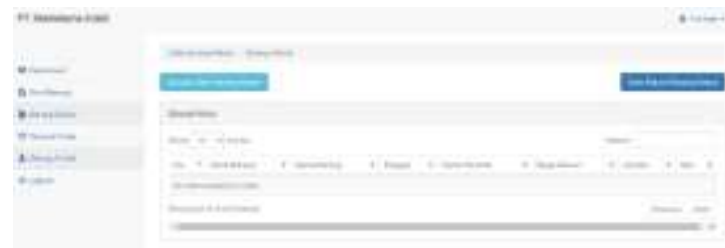

Gambar 4.29 Tampilan Barang Keluar manager

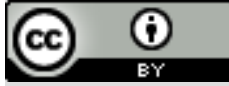

This work is licensed under a Creative Commons Attribution 4.0 International License. http://journal.stmikjayakarta.ac.id/index.php/JMIJayakarta 
DOI: $10.52362 / j m i j a y a k a r t a . v 1 i 4.569$

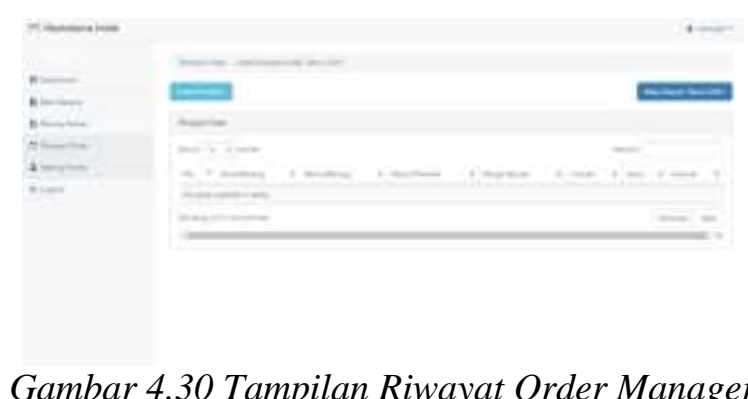

Gambar 4.30 Tampilan Riwayat Order Manager

\section{Kesimpulan}

Berdasarkan hasil analisa dan uraian pembahsan pada bab-bab sebelumnya mengenai Sistem Persediaan Bararng Pada PT.Marketama Indah dapat di diberikan kesimpulan yaitu :

1. Proses Sistem Persediaan Barang pada PT. Marketam Indah dalam menginput pendataan barang memerlukan waktu yang cukup lama karena masih menggunakan buku lalu diinput ke dalam Microsof sehingga tidak efesien dan menyebabkan ketidak kauratan karena sistem yang masih manual menghambat baik dalam pelayanan ataupun proses pembuatan laporan

2. Dengan adanya sistem usulan yang dibangun dengan metode PIECES dan sudah terkomputerisasi, sistem dapat diakses oleh pegawai dan manager untuk pengelolaan data barang juga dapat diakses sesuai kebutuhan internal perusahaan. Selain itu, juga memberikan informasi stok yang ada digudang secara cepat dan akuarat. Kemudian kinerja sistem semakin efektif, efisien, meningkatkan dalam pelayanan, dan bisa meminimalisir terjadinya human error.

\section{DAFTAR PUSTAKA}

[1] Sitiani Zalukhu1, Inge Handriani, 2019, ANALISA DAN PERANCANGAN APLIKASI SISTEM INVENTORY (STUDI KASUS: PT. CAKRA MEDIKA UTAMA), Jurnal Universitas Bengkulu (Jurnal UMB)

[2] Fitri Herawati, Yaya Sudarya Triana 2019, ANALISA DAN PERANCANGAN BOLT INVENTORY MANAJEMENT SYSTEM : PT. INTERNUX, Ensiklopedia of Journal, Lembaga Penelitian dan Penerbitan Hasil Penelitian Ensklopedia

[3] Ari Wibowo, 2020, ANALISA DAN PERANCANGAN SISTEM INFORMASI INVENTORY PENJUALAN DAN PEMBELIAN PERANGKAT KOMPUTER BERBASIS WEB (STUDI KASUS: PT. STEFAN MANDIRI PERKASA, JUKOMIKA (JURNAL ILMU KOMPUTER DAN INFORMATIKA)

[4] Siti Ernawati, 2020, Analisa Pieces Untuk Rancang Bangun Sistem Informasi Monitoring Persediaan Barang Berbasis Web Pada Koperasi Sartika Bogor, EVOLUSI

[5] Lila Setiyani, Yeny Rostiani, Tri Ratnasari, analisis Kebutuhan, 2020, Analisis Kebutuhan Fungsional Sistem Informasi Persediaan Barang Perusahaan General Trading (Studi Kasus : PT. Amco Multitech), RISET \& JURNAL AKUNTANSI, JURNAL PROGRAM STUDI AKUNTANSI POLITEKNIK GANESHA

[6] Anwardi, Anggi Ramadona, Misra Hartati, Tengku Nurainun, Ekie Gilang Permata, 2020 Analisis PIECES dan Pengaruh Perancangan Website Fikri Karya Gemilang Terhadap Sistem Promosi Menggunakan Model Waterfall, Jurnal Rekayasa \& Industri

[7] Ahmad Arif Nurrahman, 2019 Perancangan Sistem Informasi Gudang Barang Jadi di PT Remaja Rosdakarya, ETHOS (Jurnal Penelitian dan Pengabdian) 
DOI: $10.52362 / j m i j a y a k a r t a . v 1 i 4.569$

[8] Asep Muhammad Indra Purnama, 2019, PERANCANGAN SISTEM INFORMASI INVENTORI GUDANG KAIN PT. NASIONAL SANDANG TEXTILE, Jurnal Sistem Informasi

[9] Iyus Maida Manalu, Akmaludin Akmaludin, 2019, PERANCANGAN SISTEM INFORMASI INVENTORY PADA GUDANG CONSUMABLE PADA PT. UMBUL REJEKI CIKARANG, INTI NUSA MANDIRI

[10] Effan Najwaini, Purnama, Nur Rizki Aulia, 2020, Perancangan Sistem Informasi Persediaan Barang Berbasis Web pada Alzena Hijab Store Banjarmasin, Jurnal Ilmu Komputer dan Bisnis

[11] Fahrisal, Sentosa Pohan, Marnis Nasution, 2018, PERANCANGAN SISTEM INVENTORY BARANG PADA UD. MINANG DEWI BERBASIS WEBSITE, INFORMATIKA Fakultas Sains \& Teknologi Universitas Labuhanbatu

[12] Syahri Ramadhani , 2018, PIECES Framework untuk Analisa Tingkat Kepuasan Pengguna dan Kepentingan Sistem Informasi, Jurnal Teknologi dan Manajemen Informatika

[13] Lukman Nulhakim, Nur Azizah, Mety Trisna Ajija, 2018, Sistem Informasi Monitoring Inventory Dengan Analisa PIECES Pada PT Care Spundbond, Proceeding Seminar Nasional Sistem Informasi dan Teknologi Informasi

[14] Abdul Hafidh Sidiq, Ana Kurniawati 2019, ANALISIS KEBUTUHAN SISTEM ADMINISTRASI BAGIAN SIDANG UJIAN UNIVERISTAS GUNDADARMA DENGAN METODE PIECES, Jurnal Ilmiah Tejknologi Dan Rekayasa

[15] Yuntari Purba Sari, 2017, RANCANG BANGUN APLIKASI PENJUALAN DAN PERSEDIAAN OBAT PADA APOTEK MERBEN, JURNAL SISTEM INFORMASI DAN KOMPUTERISASI AKUNTANSI (JSK) 